\title{
Digging into 'the Rabbit-Hole' of the Extracellular Matrix
}

\author{
Gerald Burgstaller
}

Comprehensive Pneumology Center, University Hospital of the Ludwig Maximilians University Munich and Helmholtz Zentrum München, Member of the German Center for Lung Research, Munich, Germany

You take the red pill - you stay in Wonderland and I show you how deep the rabbit-hole goes. Morpheus, The Matrix, 1999

In its physiological context, the extracellular matrix (ECM) is a complex and highly ordered 3-dimensional meshwork of numerous fibrous and nonfibrous molecules. Its function lies far beyond mere architectural support for the anchorage of a tissue's cellular components. Biochemical and biophysical cues within the ECM are thought to steer biological processes like tissue homeostasis and morphogenesis as well as cellular differentiation, proliferation, survival and migration $[1,2]$. By and large, the ECM is composed of mostly huge and complex macromolecules such as collagens, elastin, proteoglycans, fibronectins and laminins. When analyzing these molecules experimentally, their large size, insolubility and degree of cross-linking pose huge challenges. Nevertheless, attempts to decipher the protein composition of human and mouse ECM in much more detail by combining bioinformatics and in vivo confirmation with mass spectrometry-based proteomic technology have been quite successful, revealing the matrisome of the murine lung [3]. Thus, in future, it will become more and more common to decipher the proteomic composition ("matrisome signature') of the ECM by proteomic techniques in physiological and pathological processes. To date, it is still unclear whether instructive cues within the ECM could, along with a plethora of secreted mediators, detri- mentally influence the behavior of cells finally resulting in a pathological vicious circle. The ECM parameters that might provoke a cellular reaction can be manifold: molecular composition, 3-dimensional architecture, fiber size and orientation, topology, stiffness or viscoelasticity, posttranslational modifications or matrix-associated growth factors. Booth et al. [4] demonstrated that, in the human lung, fibroblasts that were reseeded on fibrotic decellularized lung matrices derived from patients with idiopathic pulmonary fibrosis (PF) differentiate into aSMA-expressing myofibroblasts mostly by means of a TGF- $\beta$-independent mechanism [4], i.e. they attribute mechanisms that backfire to the biophysical properties of the ECM rather than to soluble inflammatory and fibrogenic mediators. This finding is supported by several studies in different settings [5-9]. Laurent et al. [10] reviewed the role of soluble mediators in disease, based on aberrant remodeling of the ECM. Wagner et al. [11] recently managed to show that human cells (i.e. bronchial epithelial cells, lung fibroblasts and mesenchymal stem cells), when reseeded on emphysematous decellularized lung scaffolds, did not persist past day 7. In contrast, on normal decellularized lung scaffolds, the same type of cells were found to be viable for up to 28 days in culture. Interestingly, when the same cells were cultured on plas-

\section{KARGER 125}

2014 S. Karger AG, Base

0025-7931/14/0891-0015\$39.50/0
Gerald Burgstalle

Comprehensive Pneumology Center

University Hospital of the Ludwig Maximilians University Munich and

Helmholtz Zentrum München, DE-81377 Munich (Germany)

E-Mail gerald.burgstaller@ helmholtz-muenchen.de 
tic dishes coated with solubilized matrix derived from emphysematous decellularized lung, no cytotoxic effects were observed. This strongly favors the existence of pernicious cues residing within the 3-dimensional microand macro-architecture of the diseased ECM rather than in its molecular composition alone. An aberrant remodeling of the ECM is a hallmark of various lung diseases. In fibrotic interstitial lung diseases, such as idiopathic $\mathrm{PF}$, the massive secretion of ECM proteins strongly deteriorates the compliance of the lung tissue. In addition, the ECM proteins are subjected to multiple posttranslational modifications (PTMs) that may have different activation patterns in the pathological state and thus contribute to the progression of disease. In the latest issue of Respiration, Kristensen et al. [12] review the PTMs (glycosylation, proteolytic cleavage, cross-linking, oxidation and citrullination) that most commonly affect ECM quality, thus contributing to the biophysics and biomechanics of the ECM in idiopathic PF. PTMs can be manifold and highly variable in different diseases or even in various stages of a disease, so deciphering the role of PTM signatures ('protein quality') will become as important as assessing the amount and composition of secreted ECM proteins ('protein quantity') in the onset and progression of PF. As reviewed by Kristensen et al. [12], proteolytically fragmented collagen and elastin molecules might, in the future, be a novel source of valid biomarkers with diagnostic and prognostic value with respect to customized treatments for idiopathic PF and chronic obstructive pulmonary disease patients. Prospectively, an understanding of the complex molecular and biophysical interplay between cells and the inherent instructive cues of natural ECM might aid the development of a surrogate ECM, either synthetic or natural, that could ultimately provide new and transplantable tissues. Furthermore, the emergence of sensitive and automated high-throughput proteomic techniques that are capable of readily detecting the signatures of both 'protein quantity and quality' within the ECM will usher in the discovery of new biomarkers.

\section{References}

$>1$ Frantz C, Stewart KM, Weaver VM: The extracellular matrix at a glance. J Cell Sci 2010; 123:4195-4200.

-2 Hynes RO: The extracellular matrix: not just pretty fibrils. Science 2009;326:1216-1219.

$\checkmark 3$ Naba A, Clauser KR, Hoersch S, Liu H, Carr SA, Hynes RO: The matrisome: in silico definition and in vivo characterization by proteomics of normal and tumor extracellular matrices. Mol Cell Proteomics 2012;11:M111 014647.

4 Booth AJ, Hadley R, Cornett AM, Dreffs AA, Matthes SA, Tsui JL, Weiss K, Horowitz JC, Fiore VF, Barker TH, et al: Acellular normal and fibrotic human lung matrices as a culture system for in vitro investigation. Am J Respir Crit Care Med 2012;186:866-876.
5 Arora PD, Narani N, McCulloch CA: The compliance of collagen gels regulates transforming growth factor-beta induction of alpha-smooth muscle actin in fibroblasts. Am J Pathol 1999; 154:871-882.

6 Goffin JM, Pittet P, Csucs G, Lussi JW, Meister JJ, Hinz B: Focal adhesion size controls tension-dependent recruitment of alphasmooth muscle actin to stress fibers. J Cell Biol 2006;172:259-268.

7 Liu F, Mih JD, Shea BS, Kho AT, Sharif AS, Tager AM, Tschumperlin DJ: Feedback amplification of fibrosis through matrix stiffening and COX-2 suppression. J Cell Biol 2010; 190:693-706.

8 Paszek MJ, Zahir N, Johnson KR, Lakins JN, Rozenberg GI, Gefen A, Reinhart-King CA, Margulies SS, Dembo M, Boettiger D, et al: Tensional homeostasis and the malignant phenotype. Cancer Cell 2005;8:241-254. $\checkmark 9$ Wang HB, Dembo M, Wang YL: Substrate flexibility regulates growth and apoptosis of normal but not transformed cells. Am J Physiol Cell Physiol 2000;279:C1345-C1350.

10 Laurent GJ, Chambers RC, Hill MR, McAnulty RJ: Regulation of matrix turnover: fibroblasts, forces, factors and fibrosis. Biochem Soc Trans 2007;35:647-651.

11 Wagner DE, Bonenfant NR, Parsons CS, Sokocevic D, Brooks EM, Borg ZD, Lathrop MJ, Wallis JD, Daly AB, Lam YW, et al: Comparative decellularization and recellularization of normal versus emphysematous human lungs. Biomaterials 2014;35:3281-3297.

12 Kristensen JH, Karsdal MA, Genovese F, Johnson S, Svensson B, Jacobsen S, Hägglund P, Leeming DJ: The role of extracellular matrix quality in pulmonary fibrosis. Respiration 2014;88:487-499. 